\title{
A QUESTÃo DO GÊNERO NA LINGUAGEM DO DISCURSO LITERÁRIO
}

\author{
Ana Raquel de Sousa Pourbaix Diniz ${ }^{1^{*}}$
}

\section{RESUMO}

DINIZ, A. R. S. P. A questão do gênero na linguagem do discurso literário. Perspectivas Online: Humanas \& Sociais Aplicadas, v.10, n.28, p.39-49, 2020.

A interligação entre gênero e Literatura são recorrentes ao longo da história e colocam no centro da discussão as sutilezas, os explícitos e os implícitos na linguagem dos discursos construídos. Neste contexto, o presente artigo tem como objetivo central desenhar uma breve análise discursiva do dizer literário e sua interface com a construção do conceito de gênero e suas implicações sociais. Assim, objetivamos investigar o capítulo "A triste história de Eredegalda", extraído da obra literária infantojuvenil "Enquanto o sono não vem", de José Mauro Brant. Por meio das concepções da Análise do Discurso, buscaremos nuances e evidências verbais que relevam um possível sinal de abuso e violência em relação à infância feminina. Por fim, analisaremos os marcadores discursivos que subjazem ao nosso recorte, tomando como referência os aspectos ideológicos do ato comunicativo e a proposta de respeito à diversidade de gênero. Nossa hipótese é a de que a literatura é um dos vetores de polarização do conceito de gênero no construto social.

Palavras-chave: Literatura; Construção Social; Violência Feminina. 


\title{
THE QUESTION OF GENDER IN THE LITERARY SPEECH LANGUAGE
}

\begin{abstract}
The interconnection between gender and literature are recurrent throughout history and put at the center of the discussion the subtleties, the explicit and implicit in language of the constructed discourses. In this context, the present article has as its central objective to make a brief discursive analysis of literary discourse and its intercession with the interface of gender concept elaboration and its social implications. Therefore, we aiam investigate is the chapter "the sad story of Eredegalda", taken from José Mauro

Come" ("Enquanto o sono não vem"). Through the ideas of discourse analysis, we will seek nuances and verbal evidence that reveal a possible sign of abuse and violence in relation to female childhood. Finally, we will analyze the discursive markers that underlie our clipping, taking as reference the ideological aspects of the communicative act and the proposal of respect for gender diversity. Our hypothesis is that literature is one of the polarization vectors of the concept of gender in the social construct.
\end{abstract} Brant's book "While Sleep Does Not

Keywords: Literature; Social Construction; Female Violence.

${ }^{1}$ Institutos Superiores de Ensino do CENSA - ISECENSA - Rua Salvador Correa, 139, Centro, Campos dos Goytacazes, RJ, CEP: 28035-310, Brasil. 


\section{INTRODUÇÃO}

$\mathrm{O}$ ato comunicativo é inerente ao ser humano. Deste modo, a sociedade é cercada por dizeres tecidos pela ecologia humana e social. Os mais variados discursos atuam como intercâmbio entre sujeito-sujeito, sujeito-mundo e sujeito-cultura. E quer seja esse discurso literário, político, religioso, acadêmico, publicitário, ele reveste-se de linguagens e estratégias linguísticas apropriadas para efetivar o diálogo entre os pilares interdependentes que constituem o ato comunicativo: emissor, código, veículo, mensagem e destinatário.

De acordo com as teorias de comunicação, o emissor é aquele que diz, que transmite um conteúdo/mensagem por meio de códigos, que podem ser verbais, visuais e/ou sonoros. A mensagem é transmitida por um veículo, a saber: um livro, uma revista impressa ou eletrônica, canal de televisão, redes sociais e outros.

Sobretudo, na Era das Tecnologias Digitais da Informação e Comunicação (TDIC), é crescente o dinamismo dos canais de comunicação. De acordo com estudos na esfera das relações públicas, Andrade (1965, p. 132) considera que há uma aproximação entre as partes comunicativas. Para ele, emissores e receptores, independentes da proximidade física, estão interligados por veículos de comunicação. O livro é um instrumento, entre tantos, que cumpre a função de ser o meio pelo qual recebemos uma informação.

Assim, podemos dizer que o comunicador atua como parte falante, aquela que deseja apresentar a uma determinada comunidade de enunciadores, ou seja, de receptoresdecifradores, o corpo semântico, a materialização da comunicação, sua mensagem.

Este trabalho tem como proposta fazer um estudo crítico do conceito de gênero e de suas respectivas manobras de linguagem que oportunizam sua interlocução com a violência da infância feminina no texto literário. Interessa-nos realizar uma leitura analítica da engenharia discursiva, ou seja, da combinação de palavras que se agregam e conversam entre si, constituindo o discurso literário, no viés das questões de gênero.

Propomos a metodologia da análise linguística, fundamentada na Análise do Discurso de Eni Orlandi. Buscaremos identificar a psicologia dos valores individuais e coletivos que permeiam as ideologias em ação no capítulo "A triste história de Enedegalda", da obra literária infantojuvenil "Enquanto o sono não vem. Investigaremos marcas que possam evidenciar um diálogo entre a construção social do conceito de gênero feminino face à violência doméstica e à Literatura.

Nossa proposta "A questão do gênero do discurso literário", investe no viés ideológico dos discursos, e, para isto, busca desvendar os múltiplos sentidos encobertos pelo hibridismo que há entre o dito literário e os marcadores de gênero. Assim, nossa pesquisa analisará a presença de uma nuance de violência na infância feminina por meio das manifestações linguísticas da obra em debate.

\section{METODOLOGIA}

Este trabalho de pesquisa compreende uma abordagem com enfoque no aspecto qualitativo, baseado na análise textual literária. Segundo Hernández Sampieri (2013, p. 33), "as pesquisas qualitativas se baseiam mais em uma lógica e em um processo indutivo (explorar e descrever, e, depois gerar perspectivas teóricas/discursivas)". Deste modo, a proposta é realizar uma análise descritica, do texto literário narrativo, sugerido para crianças de 6 a 8 anos de idade. Propomos um debate interligando a linguagem literária e a 
construção do conceito de gênero feminino - uma interface com a violência doméstica.

\title{
3. RESULTADOS
}

\subsection{Leitura da Violência Feminina Infantil no Discurso Literário}

Em uma breve leitura discursiva e literária dos principais fragmentos do capítulo "A triste história de Eredegalda", extraído da obra "E quem quiser que conte outra - Enquanto o sono não vem" (Figura 01), propomos a questão do gênero na Literatura como objeto de estudo. A abordagem do gênero na escola é desafiadora, pois exige conhecimento geral sobre o assunto, por parte dos profissionais da Educação.

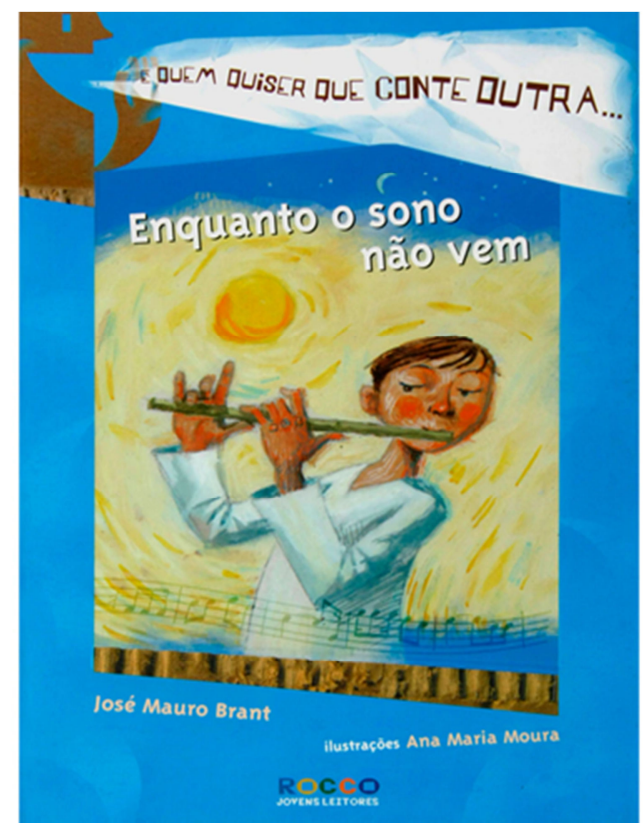

Figura 1: Capa da obra literária analisada

Observamos que a capa da obra em análise (Figura 01) não traz conteúdo visual polêmico, inapropriado para a fase da infância. Entretanto, o conteúdo verbal/linguístico merece atenção. A escola é lugar da Literatura, como afirma Coelho (2000). No entanto, é preciso avaliar a qualidade da abordagem literária, a construção da linguagem, do discurso, de modo que, o contato com a arte literária possa estimular a expressão verbal significativa e consciente.

\begin{abstract}
A escola é hoje, o espaço privilegiado, em que deverão ser lançados às bases para formação do indivíduo. É, nesse espaço, privilegiamos os estudos literários, pois, de maneira mais abrangente do que quaisquer outros, eles estimulam significados, a consciência do eu em relação ao outro, a leitura do mundo em seus vários níveis e, principalmente, dinamizam o estudo e conhecimento da língua, da expressão verbal significativa e também consciente (COELHO, 2000, p. 15-16).
\end{abstract}

Após observamos a capa da obra, analisaremos o conteúdo verbal. A seguir, a transcrição dos trechos que compõem o corpo de análise:

Eram três filhas de um rei. Todas três belas. A mais bela de todas Eredegalda se chamava. Um dia, seu pai lhe disse: -Se quiseres casar comigo, serás a minha esposa, e tua mãe, nossa criada. - Isso não, querido pai! Isso não pode ser, preferi ficar fechada do que ver minha mãe criada. Então, o rei mandou construir três torres e trancou Eredegalda dentro. Só poderia comer carne salgada, sem beber um copo de água. Eredegalda saiu chorando, chorando lágrimas de sangue. Subiu à primeira torre para ver quem avistava. 
(...) Todos três chegaram juntos, mas, Eredegalda já estava morta, acompanhada de quatro anjos e Jesus na porta (BRANT, 2013, p. 27-29).

Antes de iniciarmos a análise de conteúdo linguístico e sua interface com as questões do gênero, vale destacar que, na rede pública de ensino, a obra de autoria de José Mauro Brant, publicada pela Editora Rocco, foi distribuída pelo Ministério da Educação (MEC), em 2017, por meio do Programa Nacional do Livro Didático (PNLD) para Alfabetização na Idade Certa.

A obra foi indicada para uso nas turmas do $1^{\circ}$ ao $3^{\circ}$ ano - Ensino Fundamental, com objetivo de apoiar a alfabetização das crianças e formar leitores, faixa etária de 6 aos 8 anos de idade. No entanto, o conteúdo narrativo da obra literária "E quem quiser conte outra Enquanto o sono não vem", sobretudo o capítulo "A triste história de Eredegalda" foi questionado por profissionais do campo educacional, pesquisadores literários; desencadeando no recolhimento dos 93 mil exemplares, em todo território brasileiro, com intervenção do Ministério Público (MP), conforme consta no portal oficial do MEC.

A decisão do MEC foi ancorada no parecer técnico da Secretaria de Educação Básica (SEB), que considerou a obra inadequada por causa do conto "A triste história de Eredegalda", que trata a história de um rei que quer se casar com uma de suas filhas.

Sabemos que a linguagem literária deve ser adequada não só às competências linguísticas do aluno, mas também à experiência de vida do leitor, considerando seu nível de amadurecimento psicológico, social, emocional. Deste modo, no ciclo de alfabetização, as crianças são leitores em formação e, por conseguinte, ainda estão em processo de autonomia, maturidade, senso crítico. O trecho transcrito acima demanda um pensar mais sofisticado para problematizar a tortura psicológica de um adulto do gênero masculino frente a um ser indefeso, a criança.

A polêmica do discurso literário em debate, como evidencia no fragmento acima, retrata nuances de violência contra o gênero feminino na fase da infância. Sabemos que, de acordo com muitas pesquisas, o ambiente familiar é marcado com maior índice de violência contra a mulheres, espaço em que a vítima tem convívio permanente afetivo, muitas vezes, de parentesco, tais como: marido, pais, padrados, avôs, irmãos.

A história evidencia o ciclo da violência vivido pela personagem principal. Sendo ela uma figura do gênero feminino, sem idade identifica, com beleza exuberante que é assediada pelo próprio pai. Marca de uma sociedade patriarcal, do gênero e sua relação de poder - 0 masculino em detrimento ao feminino/ a subordinação do feminino.

O texto não diz a idade cronológica da personagem. No entanto, podemos inferir que por ser filha, possivelmente, pode ser uma criança ou adolescente. A expressão "A mais bela de todas" confirma que Eredegalda era objeto de desejo do pai, figura masculina que tortura com violência psicológica sua própria filha - "Se quiseres casar comigo, serás minha esposa, e tua mãe, nossa criada". A menina não aceita e se submete ao encrauzulamento no castelo retrato de tortura psicológica.

Podemos inferir que, após tanta violência psicológica e física (danos à saúde do corpo - má alimentação, por exemplo, como mostra o trecho "só poderia comer carnes salgadas") a menina faleceu. Da força da palavra à morte - a narrativa evidencia a trajetória de dor e violência feminina vivida por tantas mulheres na contemporaneidade. O ciclo da violência doméstica assinado pela pressão psicológica até chegar à violência física, último nível, a morte da matéria. 


\section{DISCUSSÃO}

\subsection{Lei Maria da Penha: gênese e avanços}

Em 2019, surge a Lei Maria da Penha, Lei n ${ }^{\circ} 11340$, de 07 de agosto de 2006. Neste contexto, o Senado aprovou o Projeto de Lei (LP) 17/2019 que determina medida protetiva à vítima de violência doméstica, a apreensão imediata de arma de fogo de posse do agressor.

A violência contra a mulher é histórica na sociedade. Sabemos que há inúmeros registros de lutas sociais na perspectiva de protegera mulher, principalmente contra a violência doméstica. No Brasil, ano de 2001, uma iniciativa da cearense Maria da Penha Fernandes, que acionou a Comissão Interamericana de Direitos Humanos e solicitou à corte o reconhecimento da negligência na apuração de seu caso: passados mais de 15 anos das duas tentativas de homicídio praticadas por seu ex-marido, que a deixaram paraplégica. Reconhecido como passo importante na luta contra violência feminina.

O Estado foi responsabilizado pela inércia e recaiu sobre ele a responsabilidade de criar políticas voltadas à erradicação da violência contra as mulheres no país. Assim, o projeto de lei prevendo mecanismos de combate e prevenção à violência doméstica com o apoio de um consórcio de ONGs, juristas feministas e integrantes dos movimentos de mulheres, gerou a Lei Maria da Penha. Decorrente de lutas, em especial, a luta Maria da Penha redefiniu o cenário legal e as políticas públicas em defesa da mulher brasileira.

Antes da Lei Maria da Penha, a questão da violência doméstica era tratada como problema privado, familiar. O enunciado "O privado é público!" diz respeito à mudança de paradigma - violência doméstica, direitos reprodutivos, cuidados com as crianças e a família passam a ser discutidos como questões sociais. Assim, deixam o caráter particular para ser objeto de políticas de Estado, como medidas de combate à violência, construção e manutenção de creches, mais recente, a obrigatoriedade de escolarização a partir dos 4 anos de idade, equipamentos como lavanderia e restaurantes, campanhas e distribuição de contraceptivos.

Avanços e medidas terminam por conferir à mulher o direito de controle ao seu corpo - Nosso corpo nos pertence. Refere-se à autonomia das mulheres em relação ao seu próprio corpo, como por exemplo, à mulher é delegada a opção de ser ou não mãe, bem como o direito ao prazer sexual, à sexualidade, a se vestir e se portar da forma que julgar melhor para si.

\subsection{Um Debate à Luz da Lei Maria da Penha}

A violência contra as mulheres está entre os fenômenos sociais mais visíveis na contemporaneidade, uma questão de dignidade humana e de saúde pública. O dinamismo do fenômeno exige um olhar crescente para as políticas públicas de combate à violência doméstica e familiar contra a mulher.

Neste contexto, nasce a Lei ${ }^{\circ} 11340 / 2006$, conhecida como Lei Maria da Penha. No seu artigo $5^{\circ}$, conceitua a violência doméstica e familiar como aquela que é sofrida pelas mulheres por meio de "qualquer ação ou omissão baseada no gênero que lhe cause morte, lesão, sofrimento físico, sexual, ou psicológico e dano moral e patrimonial."

De acordo com a Lei Maria da Penha há cinco tipos de violência que podem ser causados contra a mulher, a saber: física, aquela representada por atos que prejudiquem a

Persp. Online: hum \& sociais aplicada., Campos dos Goytacazes, 28 (10)39-49- 2020 seer.perspectivasonline.com.br 
saúde de seu corpo; sexual, aquela que obriga a mulher a práticas sexuais contra sua vontade; psicológica, aquela que põe em risco o psicoemocional da mulher; a patrimonial, aquela que causa destruição de objetos pessoais, de seus bens materiais; moral, todo tipo de dizer marcado pela calúnia, injúria, difamação.

Geralmente, a violência contra a mulher perpassa por três fases. Inicialmente, a fase da tensão, em que o agressor revela na face e tom de voz a agressão. A fase da exploração que traz à tona ira e até agressões físicas. Em sua última fase, o ciclo é reconhecido pela fase lua de mel, tempo da manipulação afetiva, de promessas de mudanças de comportamento, para melhor.

Caso a personagem principal, além de ser do gênero feminino, seja uma criança, temos um episódio literário de violência duplamente qualificado - violência contra a infância e contra a mulher. Assim, observamos no itinerário narrativo do capítulo especificado, o pai que deseja, pressiona e tortura sua própria filha para casar com ele, representação simbólica da realidade de tantos lares brasileiros.

Diante de um discurso, neste caso literário, a teia semântica amplia-se de acordo com a gradação de investigação e correlações que o sujeito leitor tem possibilidade de realizar. $\mathrm{O}$ leitor deve perpassar por caminhos sutis e implícitos, e operar como analista do discurso, ou seja, um detetive cognitivo, à procura de pistas, de indícios, muitas vezes camuflados em silêncio. Para Carneiro (1996, p. 8), aceitar a existência de uma dimensão implícita da significação discursiva é considerar que existe um para além do dito, isto é, uma realidade extralinguística, constituída de dados externos que agregados aos sentidos intrínsecos ampliam o campo semântico do discurso.

A impessoalidade e a neutralidade são indagadas, tende em vista que somos seres por natureza ideológicos, políticos, sociais. E mesmo entendo que o discurso literário é marcado pela ficção, pela fantasia, ele, de alguma forma, pode influenciar no imaginário simbólico das pessoas, inclusive das crianças, que segundo as teorias de aprendizagem aprendem por meio de realidades concretas. Deste modo, o livro literário é uma realidade concreta e possível, real para uma criança, até uma certa idade. Os discursos trazem marcas implícitas e explícitas de subjetividade(s), de construção de conceitos inerentes ao seu conteúdo literário.

\subsection{O Conceito de Gênero}

Atualmente, "gênero" é um conceito discutido e (re)pensado no campo dos estudos sociais. Tantas vezes generalizado, banalizado e apropriado pelo senso comum como sinônimo de "sexo". Gênero vem em do latim genus, de onde também provêm os vocábulos "gene", "gerar" e "genital". Entretanto, embora, etimologicamente, sejam termos sinônimos, como muitos outros conceitos, "gênero" tem uma construção histórica e social somada às questões da etimologia da palavra.

Anteriormente ao surgimento do conceito de gênero, o termo "sexo" incluía as categorias biológica e social. Segundo Carvalho e Rabaya (2015) até a década de 1980, utilizava-se, no Brasil, o termo "relações sociais de sexo", por influência da literatura feminista francesa, em vez de reações de gênero.

Apenas na década de 1990 que as questões de gênero ganharam visibilidade na pesquisa e na política educacional brasileira, portanto, o discurso educacional e acadêmico ainda não incorporou, ampla e rigorosamente, o conceito de gênero como construção social e cultural, estrutura e relação de desigualdade, marcador de

Persp. Online: hum \& sociais aplicada., Campos dos Goytacazes, 28 (10)39-49- 2020 
identidade dominante/dominada, subjetividade (CARVALHO; RABAYA, 2015, p. 121).

Na Linguística, o termo gênero é utilizado para designar se uma pessoa ou objeto é feminino ou masculino. Em algumas línguas, como por exemplo, a latina, existe também o gênero neutro. No inglês, expresso pelo pronome it; no alemão, das.

Nas Ciências Humanas e Sociais, o termo é datado de 1968, quando psicólogo Robert Stolller empregou o termo para diferenciar "identidade sexual" construída por pessoas que atualmente seriam chamadas de transexuais ou intersexo, de sua "identidade anatômica" (PEDRO, 2005, p.79).

$\mathrm{Na}$ análise dos fragmentos literários, que faremos logo a seguir, buscaremos ancorar nossa breve discussão no conceito de gênero como uma engenharia social e não uma arquitetura do corpo físico biológica. Consideraremos o gênero como parte das relações sociais, como construção e não inatismo. Gênero relacionado à cultura, à história e à forma social.

As questões norteadoras procuram indagar sobre a violência contra a fragilidade da infância e a figura feminina. Abordaremos a questão do gênero face à relação de poder, hierarquia, lugar social demarcado. $O$ texto literário em debate neste artigo mostra a demarcação de poder na relação homem/mulher, criança/adulto, pai/filha. A obra é mais uma provocação para estudos a respeito das relações de poder na discussão de gênero.

Em diversas sociedades, a hierarquia é de tipo patriarcal, ou seja, pessoas identificadas com o gênero masculino detêm maior parte do poder. Isso não significa, que mulheres não tenham poderes, como diz Perrot (1988, p. 168). Como nos aponta Foucault (1988, p. 91), não há poder sem resistência. Assim, é preciso resistir para ser; para ser homem, para ser mulher.

Percebemos que conceito de gênero feminino está em permanente construção. Pesquisas a respeito das mulheres e gênero surgem a partir de demandas cotidianas, naturais, muitas vezes advindas do ambiente doméstico. Diferentes lutas pelo reconhecimento de sua cidadania impulsionam estudos como esse que destaca a mulher como sujeito social, histórico, cultural; de deveres, mas, também de direitos.

Embora, Maria da Penha Fernandes tenha sido percursora na luta contra a violência doméstica no Brasil, a defesa pelos direitos das mulheres surgiu, com intensidade, no século XIX, num movimento que ficou conhecido como feminismo e também identificado como sufragismo, tendo como principal reivindicação o voto para mulheres.

Deste modo, mulheres, de vários países, inclusive brasileiras, organizaram-se por meio de manifestações públicas, petições, manifestos e jornais, em defesa do direito da participação política. No Brasil, as mulheres obtiveram o direito ao voto apenas em 1932.

\subsection{O Texto Literário para Crianças}

Como o objeto de estudo deste artigo é a questão do gênero no discurso literário infantil, traçaremos, aqui, um breve histórico do texto literário para crianças. A história da Literatura Infantil está correlacionada com a concepção de infância. Os textos literários para crianças foram produzidos somente no final do séc. XVII e durante o séc. XVIII. Anteriormente, não existia obra literária específica para o período da infância.

Assim, crianças e os adultos vivenciavam os mesmos eventos sociais e o mesmo texto literário. Diniz e Sardinha (2016, p. 74) defendem que "o estímulo à leitura se inicia no plano 
surreal, isto é, nos primeiros contatos da criança com os tradicionais livros de Literatura Infantil, parte do universo das simbologias".

O advento da burguesia e a valorização de um modelo familiar burguês traz um novo enfoque para a criança e, consequentemente, surge a educação com ênfase na transmissão de valores burgueses, por meio do discurso literário infantil. A pesquisadora Nelly Coelho diferencia a Literatura Geral da Literatura Infantil: “[...] em essência, sua natureza é a mesma da que se destina aos adultos. As diferenças que a singularizam são determinadas pela natureza do seu leitor/receptor: a criança" (COELHO, 2000, p. 29).

Assim, a Literatura Infantil surge com o intuito de disseminar ideais burgueses, centrado na valorização da vida doméstica, fundada no casamento e na educação de herdeiros, entretanto seu foco é restrito ao público infantil.

Segundo Coelho (1991, p. 5), a Literatura Infantil é

A Abertura para a formação de uma nova mentalidade, além de ser um instrumento de emoções, diversão ou prazer, desempenhada pelas histórias, mitos, lendas, poemas, contos, teatro; criadas pela imaginação poética, ao nível da mente infantil, que objetiva a educação integral da criança, propiciando-lhe a educação humanística e ajudando-a na formação de seu próprio estilo.

Para Psicanálise, a Literatura Infantil atua para além do aspecto cognitivo. Bettelhein (2007, p. 12) preconiza que a Literatura Infantil busca "desenvolver a mente e a personalidade da criança". Coelho (2000) também admite que a função da arte literária é a de afetar à criança, atuando nas suas vontades, ações, emoções, paixões, desejos, sentimentos de toda ordem:

[...]. No encontro com a Literatura (ou com a arte em geral) os homens têm a oportunidade de ampliar, transformar ou enriquecer sua própria experiência de vida, em um grau de intensidade não igualada por nenhuma outra atividade, arte é arte (COELHO, 2000, p. 29).

Entendemos a instituição escolar como território de formação humana, então cabe à mesma fomentar a leitura de textos literários, como forma de desenvolver o jeito de ser e de estar no mundo. Zibermam (2003, p 25) preconiza a respeito da relação Literatura e escola:

Preservar as relações entre a Literatura e a escola, ou o uso do livro em sala de aula, decorre de ambas compartilharem um aspecto em comum: a natureza formativa. De tanto a obra de ficção como a instituição do ensino estão voltadas à formação do indivíduo ao qual se dirigem.

A natureza formativa da Literatura na escola justifica o valor que o texto literário tem nos debates educacionais. Como uma de suas frentes, a Literatura cumpre o papel de formação de valores, e, portanto, torna-se indispensável uma análise criteriosa do conteúdo literário que subjaz uma obra indicada para leitura em sala de aula. Neste contexto, cabe destacar o papel dos profissionais da Pedagogia na arquitetura de valores humanos e sociais que perpassam as tecnologias educaticas - livros, vídeos, plataformas digitais, entre outros.

Sobre a função do pedagogo, Morellato et al. (2020, p. 66) defendem que:

O principal objetivo do pedagogo é a sua ação com fins educativos nos diferentes espaços de atuação, formando indivíduos críticos a fim da sua atuação na sociedade, tendo capacidade de criar e construir práticas que possibilitem atender às exigências de uma sociedade que está sempre em transformação.

Persp. Online: hum \& sociais aplicada., Campos dos Goytacazes, 28 (10)39-49- 2020 
Pensar a Educação é entender que o currículo é um território permeado de ideologias que envolvem a formação de crianças e jovens. E a Literatura ocupa um papel significativo na construção de valores para responder às exigências da sociedade contemporânea, em permanente mudança.

\section{5. (IN)CONCLUSÕES}

A Literatura cumpre a função de formação de leitores, mas também de despertar valores sociais e humanos, comprometidos com as relações humanas mais saudáveis. De acordo com Nelly Novaes Coelho, professora titular de Literatura Infanto-Juvenil da Universidade Federal de São Paulo, há critérios que devemos considerar ao escolhermos uma obra para um leitor. Entre eles, destacamos: a faixa etária e o nível de conhecimento geral (de mundo / de criticidade) do sujeito.

Na obra apontada, há personagens, papéis figurados, modelo de constituição familiar, com evidencias de violência contra mulher que, mesmo inspirados em histórias medievais, no universo simbólico, como ressalta o autor no término da obra, podem ser polêmicos para uma criança da faixa etária(6/8anos). O conteúdo da narrativa analisada, de forma simbólica, apresenta um conflito narrativo e personagens vivenciados por vários brasileiros.

A violência doméstica é tema de debate constante, pois ainda está presente em muitos lares e o gênero feminino é considerado alvo de torturas psicológicas e físicas, mesmo diante dos inúmeros avanços na luta pela proteção da mulher e de marco legal, como a Lei Maria da Penha, de 2006.

A Literatura é a arte de trabalhar a imaginação, em sua essência não traz compromisso com fatos reais, como o caso da violência de gênero. Como diz Coelho (2000), a Literatura Infantil é, antes de tudo literatura, ou melhor, é arte: fenômeno de criatividade, e é isto que precisa existir na sala de aula. A Literatura é um dispositivo educacional para trabalhar o simbólico, a crítica social no contexto da criatividade, do universo figurado.

Entretanto, como uma das formas de arte, a Literatura pode e dever ser um canal de consciência contra a violência feminina e outras questões sociais. Porém, dois fatores relevantes devem ser considerados na escolha do livro literário infantil: a adequação da linguagem e conteúdo da obra à faixa etária da criança e, por outro lado, o nível de conhecimento geral dos professores para tratar determinados temas na escola.

A linguagem literária pode contribuir para formação do ser humano, desenvolvendo nele a reflexão e o espírito crítico. Portanto, a apresentação de uma Literatura na escola deve ser pensada, já que o discurso literário é permeado de sutilezas, nuances, ideologias, valores humanos e sociais. Assim, a discussão continua no pensar de cada educador, pesquisador, leitor, que traçará seu próprio percurso de leitura, bem como, suas considerações a respeito do debate iniciado neste artigo.

\section{REFERÊNCIAS}

ANDRADE, T. de. Para entender relações públicas. São Paulo: Rua Miler, 734-738, 1965.

BETTELHEIM, B. A psicanálise dos contos de fadas. 22. ed. Paz e terra, 2007.

BRANT, J. M. Enquanto o sono não vem. Rio de Janeiro: JPA, 2013.

Persp. Online: hum \& sociais aplicada., Campos dos Goytacazes, 28 (10)39-49- 2020 
BRASIL. LEI MARIA DA PENHA. Lei No 11.340, de 7 de agosto de 2006.

CARVALHO, M. E. P. de; RABAY, G. Usos e Incompreensões do conceito de gênero no Brasil. Revista Estudos Feministas, Florianólis, v. 23, n. 01, p. 119-136, mar. 2015. ISSN 1806-9584

CITELLI, A. Linguagem e persuasão. São Paulo: Ática, 2002.

COELHO, N. N. Literatura infantil: teoria, análise, didática. São Paulo :Moderna, 2000.

COELHO, N. N. Panorama histórico da Literatura Infantil/Juvenil: das origens indoeuropeias ao Brasil contemporâneo. 4 ed. Ática, 1991.

DINIZ, A. R. S. P; SARDINHA, S. G. O livro impresso e a tela: a formação do leitor, linguagens e tecnologias. Perspectivas Online: Humanas \& Sociais Aplicadas, v.6, n.17, 2016.

FOUCAULT, M.. História da sexualidade. 9. ed. Rio de Janeiro: DP\&A, 2000.

HERNÁNDEZ SAMPIERI, R.; COLLADO, C. F.; LUCIO, M. P. B. Metodologia de pesquisa. Tradução por Daisy Vaz de Moraes. 5. ed. Porto Alegre: Penso, 2013.

MOREllato, J. L. H.; SIlva, M. P. A. C.; CUNHA, T. C. O.; PUGliA, V. M. S. A atuação do pedagogo nos espaços não escolares no município de Campos dos Goytacazes, RJ. Perspectivas Online: Humanas \& Sociais Aplicadas, v.10, n.27, p.63 - 832020.

ORLANDI, E. Análise do discurso: princípios e procedimentos. Campinas, São Paulo: Pontes, 2005.

PEDRO, J. M. Traduzindo debate: o uso da categoria gênero nos debates feministas. História, v. 24, n.1, França, 2005, p.77- 98.

PERROT, M. As mulheres, o poder, a história. In: Os excluídos da história: operários, mulheres e prisioneiros. Rio de Janeiro: Paz e Terra, 1988.

ZILBERMAN, R. A literatura infantil na escola. 11. ed. revista, atualizada ampliada. São Paulo: Global, 2003. 